\title{
CORRESPONDENCE
}

\section{Interrogation: has abuse been reduced by psychologists?}

SIR - Your Editorial 'Responsible interrogation' (Nature 459, 300;

2009), on involvement by psychologists in interrogation at detention centres, was misleading in several respects. You defend psychologists' participation as a protection for detainees, provided that the professional "adheres to, and is held accountable to, the most fundamental medical ethic of all: do no harm".

This ought to be the case. However, there is evidence that psychologists at some US detention centres have been consulting on the use of techniques that amount to torture and cruel, inhumane and degrading treatment, according to the United Nations Convention Against Torture, to which the United States is a signatory.

Psychologists have taught reverse-engineered Survival, Evasion, Resistance, Escape (SERE) techniques to detentioncentre personnel. The SERE programme was instigated during the Korean War in order to teach US soldiers to resist torture by the Chinese communists or North Koreans in the event of their capture. To reverse-engineer SERE is to apply the torture that the soldiers were being taught to resist.

Because of these and other abuses, the members of the American Psychological Association approved a referendum on the subject this year prohibiting psychologists' involvement in interrogations at detention centres (see http:// tinyurl.com/4xc24r). It is shocking that your Editorial does not mention that this prohibition is the American Psychological Association's policy. By not mentioning it, you leave the impression that psychologists have been helping to reduce abuse, when the data to the contrary are overwhelming. Frank Summers Psychoanalysts for Social Responsibility, 333 East Ontario, Suite 4509B, Chicago, Illinois 60611, USA

e-mail: franksumphd@hotmail.com

Readers are welcome to comment at http://tinyurl.com/mc3byy

\section{Birds and people both depend on China's wetlands}

SIR - Following your News story 'Putting China's wetlands on the map' (Nature 458, 134; 2009) and the related Correspondence 'Time for China to restore its natural wetlands' (Nature 459, 321; 2009), we also wish to stress the need to manage and protect China's existing wetlands, and to remind delegates to the International Congress for Conservation Biology, starting in Beijing on 11 July, of these globally important issues.

Eastern China supports over two million migratory waterbirds outside the breeding season, of which more than one million live in the Yangtze River floodplain. These include concentrations of eight globally threatened species, including the Siberian crane (Grus leucogeranus) and the oriental stork (Ciconia boyciana), and more than three-quarters of the east Asian populations of seven waterfowl species (L. Cao, M. Barter and G. Lei Biological Conservation 141, 2301-2309; 2008). The wetlands also supply tens of millions of people with food and raw materials, and help to prevent floods and improve water quality.

The influx of water, sediment and nutrients brought by the annual monsoon has maintained these wetlands until now, enabling humans to exploit them without disrupting their spectacular biodiversity. But hydrological changes, especially from hydroelectric and water diversion projects, and the move from lowintensity use by local people to unsustainable exploitation, have severely compromised this long-standing balance. Safeguarding China's wetland riches requires strategic regional planning, strengthening the naturereserve network and, most of all, a sound scientific understanding of the processes that support its biological diversity and its productivity.

Lei Cao School of Life Sciences, University of Science and Technology of China, 96 Jinzhai Road, Hefei 230026, Anhui, China e-mail: caolei@ustc.edu.cn Anthony D. Fox Department of Wildlife Ecology and Biodiversity, National Environmental Research Institute, University of Aarhus, Grenåvej 14, 8410 Rønde, Denmark

\section{Route for political interests to weaken conservation}

SIR - The public often question the validity and economic implications of scientific assessments of biological diversity. Various interest groups, in particular, complain because they weren't consulted. The European Commission therefore decided to open up the assessment process to online commenting, and the outcome will shortly be made public in a report. However, we believe that allowing science and politics to mix is likely to compromise biodiversity conservation.

The European Union's birds and habitats directives form a globally unique legislative framework for protecting and monitoring the status of biological diversity across national borders (see http://tinyurl.com/nk689c). In total, 25 countries have produced 8,820 scientific assessments to evaluate the current status and trends in species populations and habitats of key European interest (see http://tinyurl.com/lz3z8a). One aim of these assessments is to provide relevant scientific information to support the implementation of environmental and sustainable development policies. The information gained will help in setting up new biodiversity goals to replace the targets for 2010, which mostly remain unmet.

The European Commission's decision to include Internet-based comments in the assessment process attracted views from various interest groups and non-specialists with a political agenda. The consultation web tool was used by 170 authors in some 4,000 visits, providing several hundred informal comments on the assessments. The report will reveal the bearing that these have had on the scientific process.

Our concern is that interest groups are now able to manipulate important scientific conclusions. Member states may be persuaded to modify assessments for threatened species such as seals or wolves, for example, because these are perceived to have a harmful impact on populations of economically important species (fish and reindeer, respectively)

It might be argued that such assessments should not be left to scientists, when the political decisions resting on them concern the whole of society. However, policy-makers must base their decisions on accurate scientific information. Allowing inconvenient data to be distorted to guide decision-making could mask important early warning signs.

Science and politics must be kept separate. The task of scientists is to provide transparent information. The task of politicians is to evaluate this information in the light of society's interests before making their decisions. Don't let biodiversity conservation be undermined by political tainting of scientific endeavour. Petri Ahlroth Finnish Environment Institute, PO Box 140, 00251 Helsinki, Finland Janne S. Kotiaho Centre of Excellence in Evolutionary Research, Department of Biological and Environmental Science, PO Box 35, University of Jyväskylä, 40014 Jyväskylä, Finland, and Natural History Museum, PO Box 35, University of Jyväskylä e-mail:janne.kotiaho@jyu.fi 